\title{
EFFECT OF CU-CO MIXED METAL OXIDES ON THE COMBUSTION OF PSAN-HTPB BASED SOLID PROPELLANTS
}

\author{
Rajan Lakra ${ }^{1}$, Eshwar Reddy Cholleti ${ }^{2}$, Puran Chandra Joshi ${ }^{3}$, Narendra Yadav ${ }^{4}$ \\ ${ }^{1}$ Student, M.E in Space Engineering and Rocketry, Birla Institute of Technology-Mesra, Ranchi, India \\ ${ }^{2}$ Student, M.Tech in Thermal Engineering, JNTU-Hyderabad, Telengana, India. \\ ${ }^{3}$ HOD \& Professor, Space Engineering and Rocketry, Birla Institute of Technology-Mesra, Ranchi, India \\ ${ }^{4}$ Research Scientist-III, Space Engineering and Rocketry, Birla Institute of Technology-Mesra, Ranchi, India.
}

\begin{abstract}
Composite propellants based on ammonium perchlorate $(A P)$ as oxidizer are state-of-the-art. However, global environmental impact restricts AP-based propellants because of their high chlorine exhaust. Therefore, efforts are on to innovate propellants with clean exhaust. Ammonium nitrate (AN) has, thus, regained importance in the field of propellants and explosives, more specifically in insensitive formulations, because of its clean burning and low hazard. However, the stumbling block for the application of AN - as solid propellant oxidizer has been its dimensional instability caused by phase transformation which results in increase of volume and porosity of the propellant grain. This can be overcome by the use of phase stabilized ammonium nitrate (PSAN). In the present study AN phase stabilized by incorporating $10 \% \mathrm{KN}$ to prepare composite solid propellant. Copper-Cobalt mixed metal oxides have been synthesized via citric acid complexing method. Three different catalysts were prepared with different $\mathrm{Cu}$-Co molar ratios 1, 0.5 And 2 in the initial reactants. The synthesized catalysts were then added to the PSANHTPB(Phase Stabilized Ammonium Nitrate- Hydroxyl Terminated Poly-Butadiene) composite formulations. These propellant samples were subjected to burn rate measurement in a Crawford High Pressure Strand Burner and thermal degradation studies in Simultaneous Thermal Analyzer (STA). The thermal decomposition and burn rate of the propellant is observed maximum on the addition of Copper-Cobalt mixed metal oxide catalyst with molar ratio 2. A total of six propellant samples catalyzed and noncatalyzed and one preheated virgin sample were undertaken for the above analysis and results obtained are discussed. It has been observed that except the propellant sample with $\mathrm{Cu}$-Co-III and virgin propellant where PSAN was prepared by solid mixing, other propellant samples were hard to burn.
\end{abstract}

KeyWords:Solid propellants, Ammonium nitrate, Phase stabilization, Burn rate, Thermal decomposition, Mixed metal oxides, Catalytic combustion.

\section{INTRODUCTION}

AN has drawn a considerable amount of attention due to its low cost, smokeless, availability and comparatively less toxic exhaust. It is also a chlorine free oxidizer. Its principle use is with low burning rate, low performance rocket and gas generator as it is having poor ignitability and low performance. Another drawback of ammonium nitrate is its phase instability with temperature. So it is essential to make it phase stabilized before it is used as solid oxidizer. In the present work the phase stabilized ammonium nitrate (PSAN) was prepared by adding $10 \% \mathrm{KN}$ in saturated solution of $\mathrm{AN}$ and subsequently evaporating the water to get crystallinePSAN. This PSAN was used in all the propellant samples prepared in the present work except in one virgin sample where PSAN was prepared by solid mixing method. An attempt has been made to synthesize the copper cobalt mixed metal oxides in three different molar ratios by citric acid complexing method. Three mixed metal oxides were synthesized using molar ratios of copper nitrate tri-hydrate and cobalt nitrate hexa-hydrate.

The total six propellant compositions were processed using HTPB fuel binder, PSAN oxidizer and mixed metal oxide catalysts. These propellants were subjected to burn rate study using Crawford High Pressure Strand Burner. Thermal analysis was also carried out for AN, PSAN, virgin propellants and catalyzed propellants. Attempts have been made to analyze the data and some important conclusions drawn from present experiment are highlighted.

\section{EXPERIMENTAL}

The experimental section of the current research includes phase stabilization of ammonium nitrate (AN), grinding and sieving of AN, synthesis of mixed metal oxide catalysts, formulation and processing of composite solid propellant with and without catalysts, burn rate measurement and thermal decomposition study of the oxidizer and prepared solid propellant.

\subsection{Phase Stabilization of Ammonium Nitrate (PSAN)}

Use of $\mathrm{AN}$ in the field of rocket propulsion may be a better choice as it is cheap, easily available and non-toxic ecofriendly smokeless products which is the need of present 
scenario ,but it has some disadvantages like low burning, phase changes at different phase transformation temperature and hygropicity. And if we neutralize these negative natures of AN, it may become the best choice as an oxidizer for the solid rocket propellant.

There are lots of chemicals used to stabilize the phase changes of AN such as potassium fluoride, potassium nitrate $(\mathrm{KN})$, boric acid, ammonium sulphate, ammonium orthophosphate, magnesium nitrate, etc. The amount of chemical used to stabilize the AN varies from $0.5 \%$ to $15 \%$ of the AN. These chemicals can be added by solid mixing, solution mixing or by spray.

As AN changes its phase at several phase transformation temperatures, causes the slight change in volume so to avoid that the phase stabilization has been done by adding $10 \%$ $\mathrm{KN}$ in aqueous solution of $\mathrm{AN}$ and then the solution was kept for drying to get crystalline solid form.

The process involved weighing of $\mathrm{AN}$ and $\mathrm{KN}$ which are provided by Central Drug House New Delhi. Digital weighing machine was used to weigh accurately. $1 \mathrm{~kg}$ AN was added to $250 \mathrm{ml}$ of water and the mix was stirred till all the AN dissolved. To facilitate the mixing, the mixing temperature was kept $80^{\circ} \mathrm{C} .10 \% \mathrm{KN}$ was added and continued stirring for again 15-20 min or till it dissolved. A clear and colorless aqueous solution was obtained. The solution was spread in a steel tray and kept in oven at 55$60^{\circ} \mathrm{C}$ for drying for $14-18$ hours. A dry solid crystalline was obtained. The same process and the weight percentage of $\mathrm{AN}$ and $\mathrm{KN}$ was repeated whenever the PSAN was required. To make a separate propellant sample $200 \mathrm{gm}$ of AN was also stabilized by solid mixing method. Here also the $10 \%$ $\mathrm{KN}$ was added same as in solution mixing.

As the dry crystalline solid PSAN was obtained in the phase stabilization process, so to make it usable for processing of the propellant and to obtain the bi-modal of $\mathrm{AN}$, It was grinded by using micro-palvarizer. It was sieved by using different mess sieves in a sieve shaker. PSAN retained on 60 mess and 100 mess was used for processing the propellant. The approximate particle size of PSAN used was 250 microns and 150 microns.

\subsection{Synthesis of $\mathrm{Cu}-\mathrm{Co}-\mathrm{O}$ Mixed Metal Oxides}

All the chemicals for the experiment were of analytical grade and were used without further purification. Three different mixed metal oxides were synthesized containing different $\mathrm{Cu}-\mathrm{Co}$ molar ratios in the initial reactants. In a typical synthesis, copper(II) nitrate trihydrate $\left(\mathrm{Cu}\left(\mathrm{NO}_{3}\right)_{2} \cdot 3 \mathrm{H}_{2} \mathrm{O}\right)$ and cobalt(II) nitrate hexahydrate $\left(\mathrm{Co}\left(\mathrm{NO}_{3}\right)_{2} \cdot 6 \mathrm{H}_{2} \mathrm{O}\right)$ were dissolved in $25 \mathrm{ml}$ distilled water in china dish to obtain a mixed metal nitrate aqueous solution. Then citric acid was added to these solutions. After stirring for $10 \mathrm{~min}$ each, the solutions were heated at $105^{\circ} \mathrm{C}$ for 4 hours in hot air oven to evaporate the water solvent to produce viscous gels.

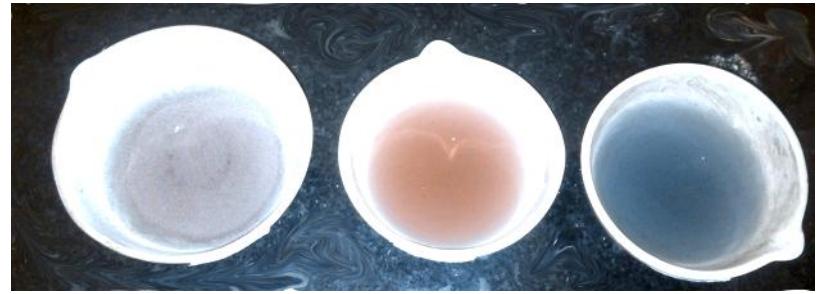

Plate-1: Initial stage of synthesis

The gels were then dried at $165^{\circ} \mathrm{C}$ in a muffle furnace for 2 hours. The resulting mass was the bubbly dark powders. The precursors were successively heated at $600^{\circ} \mathrm{C}$ for 3 hours to obtain final black copper cobalt mixed metal oxides. The same synthesis process has been carried out to get the required amount of catalysts. In a single synthesis around 0.3 to 0.4 grams of one sample catalyst was collected. These three metals oxides were then stored in separate sealed containers to avoid external effects.Table1 shows the catalysts prepared inthe present work. And above plate 1shows the initial stage of catalytic synthesis.

TABLE -1 :COMPOSITION OF COPPER COBALT MIXED METAL OXIDES

\begin{tabular}{|l|c|c|c|c|}
\hline Catalyst & $\begin{array}{l}\text { Copper } \\
\text { nitrate(gm) }\end{array}$ & $\begin{array}{l}\text { Cobalt } \\
\text { nitrate(gm) }\end{array}$ & $\begin{array}{l}\text { Citric acid } \\
(\mathrm{gm})\end{array}$ & $\begin{array}{l}\text { Molar } \\
\text { ratio(Cu/Co) }\end{array}$ \\
\hline $\mathrm{Cu}-\mathrm{Co}-\mathrm{I}$ & 0.6 & 0.72 & 3.15 & 1.0 \\
\hline $\mathrm{Cu}-\mathrm{Co}-\mathrm{II}$ & 0.6 & 1.44 & 3.15 & 0.5 \\
\hline $\mathrm{Cu}-\mathrm{Co}-\mathrm{III}$ & 1.2 & 0.72 & 3.15 & 2.0 \\
\hline
\end{tabular}

\subsection{Processing of Solid Propellants}

The required amount of Ammonium Nitrate in coarse to fine ratios 75:25, HTPB, DOA, IPDI were properly weighed. The mixing was done at $60^{\circ} \mathrm{C}$. HTPB was heated in a bearer using vex bath. Mixing was started by dehumidifying the HTPB and DOA and then mixing thoroughly by stirring for 10 minutes. The IPDI was added in the mix and stirred for again 10 minutes. Ammonium Nitrate coarse and then fine was added in slots and the mixing was done for around 30 minutes to get consistent slurry.

The propellant slurry was casted in Aluminum flat plate mold which was properly cleaned, greased and was covered by aluminum foil for easy removal of propellant sheets. After casting the slurry, the mold was kept on vibrator for around 30 minutes to remove voids which were formed during casting. The mold was kept in an electric vacuum oven at $60^{\circ} \mathrm{C}$ for a period of 6 days to allow the propellant to cure and attain the required mechanical strength. The mold was then taken out from the oven and the propellant was removed from mold. It was cleaned and stored in desiccator to avoid the absorption of moisture from atmosphere. 
Table -2: Composition of solid propellants

\begin{tabular}{|c|c|c|c|c|c|c|}
\hline PSAN & HTPB & DOA & IPDI & Cu-Co-I & Cu-Co-II & Cu-Co-III \\
\hline 75 & 18.92 & 4.6 & 1.46 & - & - & - \\
\hline 75 & 18.92 & 4.6 & 1.46 & 2 & - & - \\
\hline 75 & 18.92 & 4.6 & 1.46 & - & 2 & - \\
\hline 75 & 18.92 & 4.6 & 1.46 & - & - & 2 \\
\hline 75 & 18.92 & 4.6 & 1.46 & - & - & - \\
\hline 80 & 15.14 & 3.68 & 1.168 & - & - & - \\
\hline
\end{tabular}

All quantities are in weight Percentage

\subsection{Materials and Methods}

Simultaneous Thermal Analysis refers to the simultaneous application of Thermo Gravimetric Analysis (TGA) which is also called Thermogravimetry and Differential Scanning Calorimetry (DSC) to the same sample in the same instrument. In the present experiment Netzsch STA 409 PC Luxx was used. The temperature range of STA is ambient to $1100^{\circ} \mathrm{C}$ for the model Netzsch STA 409 PC Luxx. Heating rate is $0.01-60^{\circ} \mathrm{C} / \mathrm{min}$ and uses nitrogen atmosphere.

Crawford Burner is an apparatus used to determine the burn rate of a solid rocket propellant in an elevated pressure environment. The propellant that is being tested is called a strand and is burned in a pressurized tank called a firing vessel. The strand is a thin bar of propellant which is coated so that the burning cross-sectional area is restricted. The strand is electrically ignited at one end and the duration of time for which it burns along the length is measured with the help of fuse wires embedded in the strand. These wires are connected to the timer via an electric relay. When the first wire cuts, the timer unit starts and when the second wire is cut, it stops. The burn time is recorded and the burn rate is determined with the help of burn time and burn length. The schematic of the Crawford strand burner setup is given in figure- 1 . The burn rate measured is typically $4-12 \%$ less than the actual burn rate observed in rockets because the high temperature condition that is prevalent in actual rockets is not simulated.

\section{Details of the Crawford Strand Burner}

Model \& Make: Indigenously made by BIT, Mesra, India

Micro Palvarizer was used to grind the PSAN to get the two different size ranges of oxidizer particles which were $150 \mu$ and $250 \mu$ to get the maximum fraction loading while propellant processing.

Sieve shakers are used to collect the different collect the oxidizer particle sizes which can be defined by mesh sizes i.e., hole per squire inches in the sieves.

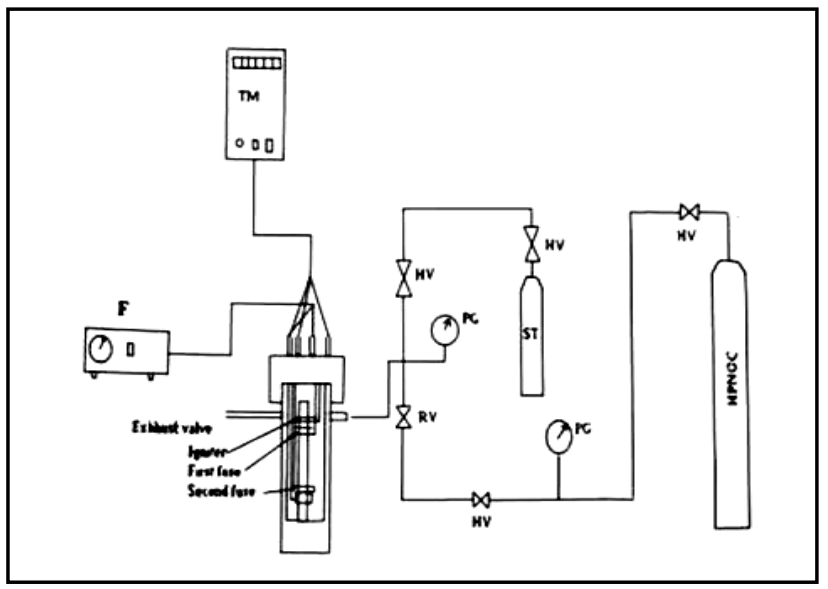

Fig-1: Crawford high pressure strand burner

\section{RESULTS AND DISCUSSION}

Mixed metal oxide catalyst has very high potential to enhance the decomposition of composite solid propellants. The present study aims to synthesize copper-cobalt mixed metals oxides with different $\mathrm{Cu}-\mathrm{Co}$ molar ratios $(1,0.5$ and 2 ) in the initial reactants and evaluate the effect of these mixed metal oxides on the combustion characteristics of PSAN-HTPB based composite solid propellants. Citric Acid (CA) complexing method was used to synthesize the copper cobalt mixed metal oxides. Well-0 synthesized mixed metal oxides were obtained after the $\mathrm{CA}-\mathrm{Cu}-\mathrm{Co}$ precursors were calcined at $60^{\circ} \mathrm{C}$ for 3 hours. The propellants used in the present study consisted of $80 \%$ PSAN and $75 \%$ PSAN. The remaining were fuel binder, plasticizer, curing agent and catalyst in a definite proportion. The ammonium nitrate was made phase stabilized by incorporating $10 \%$ potassium nitrate.

The present work centered around the study of thermal behavior of propellant sample as well as oxidizer and burning rate of propellants formulated.

\subsection{Thermal Analysis}

Thermal decomposition studies of any substance gives valuable information about the condensed phase and gaseous phase combustion processes in the combustion reaction. In the present work, the thermal degradation analysis was carried out for all the propellant samples i.e. virgin PSAN-HTPB propellant, virgin preheated PSANHTPB propellant, (Solid mixed) PSAN-HTPB propellant, PSAN-HTPB $80 / 20$ propellant, PSAN-HTPB with $2 \%$ $\mathrm{Cu} / \mathrm{Co}-\mathrm{I}$, PSAN-HTPB with $2 \% \mathrm{Cu} / \mathrm{Co}-\mathrm{II}$, PSAN-HTPB with $2 \% \mathrm{Cu} / \mathrm{Co}-\mathrm{III}$ and AN, PSAN, PSAN prepared by solid mixing, PSAN stored for 3 months and PSAN stored for 3 months and preheated. The results are presented in figure-25. The heating rate in all the experiments was kept at $10^{\circ} \mathrm{C} / \mathrm{min}$ and the heating was done up to $1000^{\circ} \mathrm{C}$. The individual TGA and DSC test have been carried out and the comparisons graphs are shown here for the both oxidizer, modified oxidizer, propellant samples and catalyzed propellant samples as mentioned above. 
TGA of pure AN describes weight loss of it on heating it from room temperature $28^{\circ} \mathrm{C}$ to $600^{\circ} \mathrm{C}$. It is observed thatit starts decomposing from temperature $220^{\circ} \mathrm{C}$ and the almost complete decomposition occurs by $303^{\circ} \mathrm{C}$. A total of $90.22 \%$ mass is decomposed in this temperature range. Further heating does not show any weight loss till $600^{\circ} \mathrm{C}$.

TGA of PSAN describes weight loss of PSAN with the temperature up to $900^{\circ} \mathrm{C}$. It is observed that the weight loss occurs in two different temperature ranges. Weight loss about $81.32 \%$ occurs in the temperature range $180-330^{\circ} \mathrm{C}$. Then the next weight loss about $11 \%$ occurs in the temperature range $540-780^{\circ} \mathrm{C}$. The total weight loss is around $92.32 \%$ till $800^{\circ} \mathrm{C}$. This two temperature decompositions may be due to the different temperature for the decomposition of $\mathrm{AN}$ and $\mathrm{KN}$.

TGA of preheated PSAN describes weight loss of PSAN in the temperature up to $1000^{\circ} \mathrm{C}$.In this case the PSAN was heated at $60^{\circ} \mathrm{C}$ for 3-4 hours before subjecting it for thermal analysis. It is observed that the weight loss occurs in the two different temperature ranges. Weight loss about $89 \%$ occurs in the temperature range $200-340^{\circ} \mathrm{C}$. The next weight loss about $8.70 \%$ occurs in the range $575-800^{\circ} \mathrm{C}$.

TGA of solid mixed PSAN describes the weight loss of PSAN up to $500^{\circ} \mathrm{C}$. In this case the PSAN was prepared by solid mixing process. Weight loss occurs in one time decomposition. Decomposition starts at $150^{\circ} \mathrm{C}$ and ends by $350^{\circ} \mathrm{C}$ then no change in weight occurs. About $88.87 \%$ of mass loss occurs in this temperature range.

A comparison of TGA thermogram in the temperature range up to $350^{\circ} \mathrm{C}$ for AN, PSAN (Prepared by solution mixing/ solid mixing) and PSAN preheated is presented in fig 2. Pure AN decomposes up to $90.22 \%$ by $305^{\circ} \mathrm{C}$. The PSAN made by solid mixing method the $88.9 \%$ decomposition takes place by $285^{\circ} \mathrm{C}$. The decomposition temperature range changes when $\mathrm{AN}$ was made phase stabilized by the addition of $\mathrm{KNO}_{3}$ solution mixing method/ solid mixing method Freshly prepared PSAN decomposes up to $81.32 \%$ by $290^{\circ} \mathrm{C}$ however PSAN stored for 3 months, the decomposition temperature range extends further. About $81.32 \%$ and $89 \%$ decomposition occur by $310^{\circ} \mathrm{C}$ for preheated and non-heated samples.

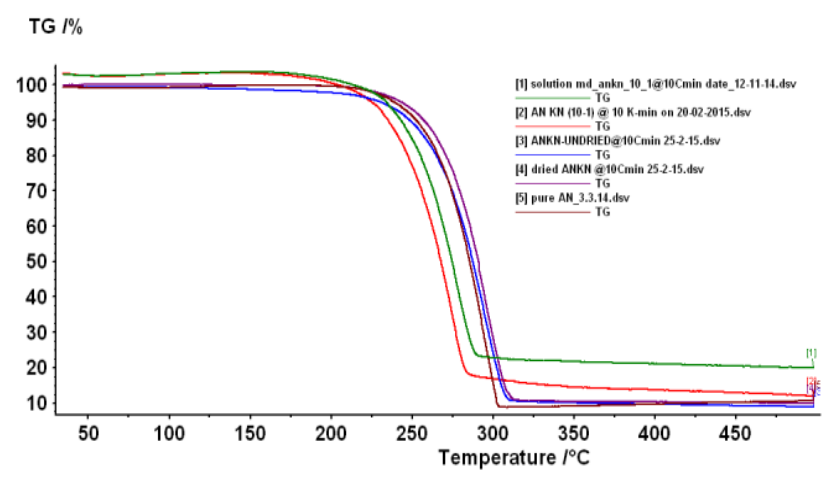

Fig-2: TGA analysis of Oxidizers
The description of TGA thermograms for all the propellant samples prepared in the present work are mentioned below and a comparison TGA thermogram showing the different weight loss of propellant samples as shown in fig-4.These thermograms highlight that propellant sample shows the \% weight loss in 3-4 different temperature ranges. The rate of weight losses in these temperature ranges is different. The weight loss in the first temperature range may be attributed to the removal of moisture and some low temperature volatile ingredients present in the propellant sample. The major weight loss occurs in the temperature range $175^{\circ} \mathrm{C}$ to $600^{\circ} \mathrm{C}$ as a result of decomposition and removal of decomposition products of PSAN as well as the evaporation and degradation of polymeric fuel binder, plasticizer and curing agents and also the reaction products. It is noticed that the rate of decomposition is higher in the first two temperature ranges.

TGA thermogram for virgin PSAN-HTPB propellant sample describes the weight loss in the temperature range $28^{\circ} \mathrm{C}$ to $1000^{\circ} \mathrm{C}$. The weight loss occurs in three decomposition temperature ranges. The decomposition starts $175^{\circ} \mathrm{C}$ and about $24.32 \%$ mass loss occurs by $225^{\circ} \mathrm{C}$. About $42.82 \%$ weight loss occurs in between $225-280^{\circ} \mathrm{C}$. The finally about $26.09 \%$ weight loss occurs in the temperature range $280-525^{\circ} \mathrm{C}$.

TGA thermogram of virgin PSAN-HTPB propellant sample weight loss of it in the temperature from $0-600^{\circ} \mathrm{C}$ which was preheated at $60^{\circ} \mathrm{C}$ for $2-3$ hours before subjecting to thermal decomposition studies. Weight loss occurs in four stages. Decomposition starts at $175^{\circ} \mathrm{C}$ and about $12.82 \%$ weight loss occurs by $220^{\circ} \mathrm{C}$. Second stage decomposition continues from $220^{\circ} \mathrm{C}$ and about $56.82 \%$ weight loss occurs by $280^{\circ} \mathrm{C}$. On comparing above two thermograms of propellant unheated and heated, it is seen that nearly the same weight loss (about $93 \%$ ) occurs by $600^{\circ} \mathrm{C}$. It is noticed that preheated sample reveals four temperature range of varying decomposition range whereas non-heated sample three temperature range of different decomposition rate.

TGA of PSAN-HTPB 80/20 virgin sample describes weight loss of it in the temperature up to $700^{\circ} \mathrm{C}$. Weight loss occurs in three temperature ranges. Decomposition starts at $175^{\circ} \mathrm{C}$ and about $12.08 \%$ weight loss occurs by $220^{\circ} \mathrm{C}$. It continues decomposing and about $58.85 \%$ of weight loss occurs by $260^{\circ} \mathrm{C}$. Then further weight loss about $17.97 \%$ occurs at slower rate till $600^{\circ} \mathrm{C}$.

TGA of PSAN-HTPB propellant sample describes the weight loss of it in the temperature up to $700^{\circ} \mathrm{C}$. In this case PSAN was prepared by solid mixing method. Weight loss occurs in three stages. Decomposition starts at $175^{\circ} \mathrm{C}$ and about $18.60 \%$ weight loss occurs by $220^{\circ} \mathrm{C}$. The decomposition continues and about $57.39 \%$ weight loss occurs by $260^{\circ} \mathrm{C}$. It continues at slower rate after $260^{\circ} \mathrm{C}$ and about $22.57 \%$ weight loss occurs by $600^{\circ} \mathrm{C}$.

A comparison of above four virgin PSAN-HTPB propellant samples have been taken in the first two stages of 
decomposition where the rapid weight loss occurs. It is observed that the \% weight loss of propellants differs markedly with shifting the decomposition temperature. The total weight losses are $67.14 \%, 69.64 \%, 70.93 \%$ and $75.99 \% .67 .14 \%$ is up to $2^{\text {nd }}$ temperature range for virgin PSAN-HTPB propellant. When the same was preheated for 2-3 hours at $60^{\circ} \mathrm{C}$ before subjecting it to thermal analysis about $2.5 \%$ higher mass loss was seen as compared to unheated propellant up to $2^{\text {nd }}$ temperature range. $3.79 \%$ higher weight loss occurs when the oxidizer $\%$ increased by $5 \%$. $8.85 \%$ higher weight loss occurs up to $2^{\text {nd }}$ temperature range when the PSAN was prepared by solid mixing method for the virgin PSAN-HTPB propellant formulation.

TGA for PSAN-HTPB propellant with $2 \% \mathrm{Cu}$-Co-I catalyst shows the weight loss of it in the temperature from $0-600^{\circ} \mathrm{C}$. Three stages decomposition is noticed. The weight loss starts from $150^{\circ} \mathrm{C}$ and about $27.54 \%$ weight loss is completed by $230^{\circ} \mathrm{C}$. There is $35.84 \%$ decomposition between $230^{\circ} \mathrm{C}$ and $265^{\circ} \mathrm{C}$. Next the slow decomposition is noticed in the temperature range $265^{\circ} \mathrm{C}$ and $600^{\circ} \mathrm{C}$ where about $27.85 \%$ weight loss occurs. It is also noticed that nature of weight loss curveis similar to curve of non-heated and preheated virgin PSAN-HTPB propellant in the temperature range $150-260^{\circ} \mathrm{C}$. However the rate of weight loss slowed down in the nest temperature range. These results indicate that $\mathrm{Cu}-\mathrm{Co}-\mathrm{I}$ de-accelerates the decomposition rate of PSAN-HTPB based solid propellant.

TGA for PSAN-HTPB propellant containing 2\% Cu-Co-II catalyst represents the weight loss with temperature up to $1000^{\circ} \mathrm{C}$. In this case decomposition occurs in fourstages. There is $24.72 \%$ weight loss in the temperature range 150 $230^{\circ} \mathrm{C}$. It is observed that the decomposition process isfaster in the second temperature range and $40.89 \%$ mass loss occurs in between $230-275^{\circ} \mathrm{C}$. There is $16.73 \%$ decomposition between $275^{\circ} \mathrm{C}$ and $425^{\circ} \mathrm{C}$. It continues decomposing at slow rate and $14.95 \%$ weight loss occurs between $425-600^{\circ} \mathrm{C}$. The weight loss rate in the $2^{\text {nd }}$ temperature range is very fast for a short duration then slows down asin the propellant sample with $2 \% \mathrm{Cu}$-Co-I.

TGA for PSAN-HTPBpropellant with $2 \% \mathrm{Cu}-\mathrm{Co}-\mathrm{III}$ describes the weight loss of it in the temperature up to $600^{\circ} \mathrm{C}$ as shown in fig-3.Three stages decomposition process is observed in this case also. In the first stage about $18.57 \%$ decomposition occurs between $180^{\circ} \mathrm{C}$ and $230^{\circ} \mathrm{C}$. After that the decomposition rate increases and about $58.09 \%$ weight loss is noted in between $230^{\circ} \mathrm{C}$ and $250^{\circ} \mathrm{C}$. Finally there is $13.50 \%$ decomposition between $250^{\circ} \mathrm{C}$ and $510^{\circ} \mathrm{C}$. A total about $92.16 \%$ decomposition occurs by $600^{\circ} \mathrm{C}$.

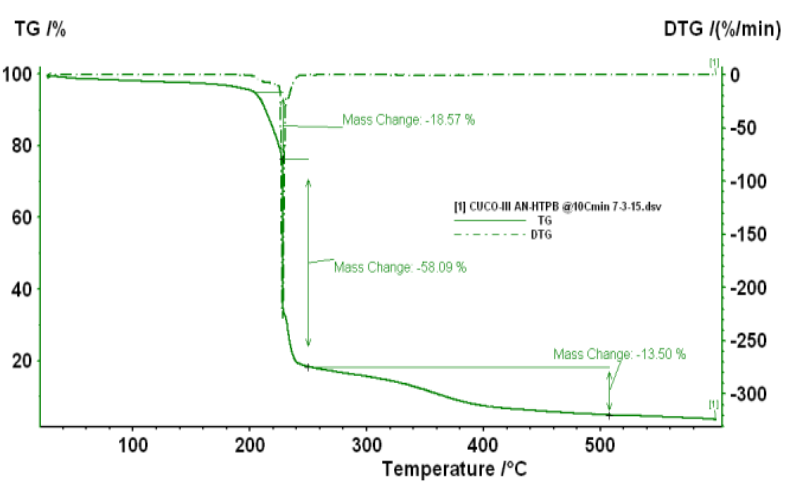

Fig-3: TGA thermogram of propellant sample with catalyst III

A comparison of weight loss results in all above catalyzed and non-catalyzed propellant shows that the weight loss is highest in the secondtemperature for all the propellant samples studied in the present work. The percentage of residues left for above mentioned propellant samples are $5.77 \%, 7.01 \%, 11.10 \%, 1.44 \%, 8.77 \%, 2.71 \%, 7.84 \%$ respectively after $600^{\circ} \mathrm{C}$.

The TGA Thermograms of all the propellant samples have been presented for comparison purposes in figure 4 . The TGA Thermograms of solution mixing virgin propellant samples and propellant sample with $\mathrm{Cu}-\mathrm{Co}-\mathrm{I}$ and $\mathrm{Cu}-\mathrm{Co}-\mathrm{II}$ catalysts are almost similar whereas the TGA thermograms of solid mixed virgin propellant and the propellant with $2 \%$ $\mathrm{Cu}$-Co-III differs from remaining all other thermograms but their nature is similar. All the thermograms show either a three or a four stage decomposition in which the catalytic activity is highest in the second stages. The weight losses in the virgin solid mixed PSAN-HTPB propellant and propellant sample with $2 \% \mathrm{Cu}$-Co-III have higher and also higher decomposition rate in the second stage as compare to other catalyzed and non-catalyzed propellant samples. It is also noticed that decomposition temperatures have shifted for PSAN-HTPB propellant with $2 \% \mathrm{Cu}-\mathrm{Co}-\mathrm{III}$ in the lower temperature side. These results indicate that the solid mixing is effective method for phase stabilization of $\mathrm{AN}$ and to improve the decomposition behavior of PSAN-HTPB solid propellant the mixed metal oxide catalyst $\mathrm{Cu}$-Co-III has potential effect.

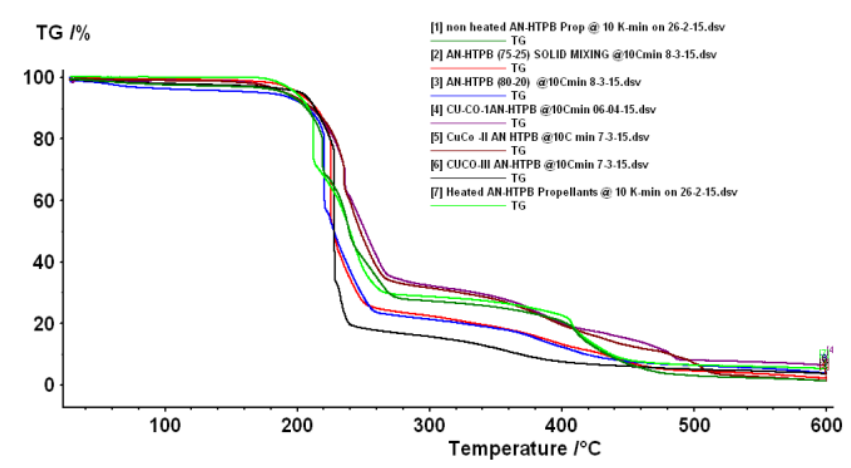

Fig-4 :TGA of propellant samples 


\subsubsection{DSC of Oxidizer}

In Differential Scanning Calorimetry, the instantaneous temperature of a sample is compared with the same sample in inert reference material during the programmed change of temperature. The temperature should be the same until thermal event occurs, such as melting, decomposition or change in the crystal structure. In an endothermic event takes place within the sample, the temperature of the sample will vary with that of the reference so a minimum variance will be observed on the curve with respect to reference. On the contrary, if an exothermal event takes place, then the temperature of the sample will exceed that of the reference and a maximum variance will be observed on the curve.

DSC test shows that $\mathrm{AN}$ reveals four endothermic peaks on the heating from room temperature $28^{\circ} \mathrm{C}$ to $600^{\circ} \mathrm{C}$. The first two endothermic peaks with the onset temperature $59.14^{\circ} \mathrm{C}$ and $134.4^{\circ} \mathrm{C}$, respectively, are observed due to two phase transformation of pure AN. The third endothermic peak having an onset temperature of $170.6^{\circ} \mathrm{C}$ represents the absorption of heat for the melting of AN. The $5^{\text {th }}$ endothermic peak whose onset temperature is $302.2^{\circ} \mathrm{C}$ represents the absorption of heat for the final and complete decomposition. These results are in confirmation of TGA curve.

DSC curve for PSAN reveals five endothermic peaks on heating it from room temperature $28^{\circ} \mathrm{C}$ to $500^{\circ} \mathrm{C}$. The first two endothermic peaks with onset temperature as $120.2^{\circ} \mathrm{C}$ and $130.2^{\circ} \mathrm{C}$ are observed, respectively to the two phase modification of PSAN. The third endothermic peak, having an onset temperature of $159.7^{\circ} \mathrm{C}$ represents the absorption of heat for the melting of PSAN. And the fourth and fifth endothermic peaks with onset temperature $207^{\circ} \mathrm{C}$ and $282^{\circ} \mathrm{C}$ shows the heat absorption for the final and complete decomposition of PSAN.

DSC curve for preheated PSAN also shows the different phase changes of it. In this case also four endothermic peaks are obtained on heating from room temperature $28^{\circ} \mathrm{C}$ to $1000^{\circ} \mathrm{C}$. The first two endothermic peaks with onset temperature as $120.5^{\circ} \mathrm{C}$ and $132.9^{\circ} \mathrm{C}$ are observed respectively due to the phase transformation of PSAN. The third endothermic peak with onset temperature $163.4^{\circ} \mathrm{C}$ represents the absorption of heat for the melting of PSAN. Fourth endothermic peak with onset temperature $303.5^{\circ} \mathrm{C}$ shows the heat absorption for the final and complete decomposition of PSAN.

DSC curve for PSAN made by solid mixing, reveals four endothermic peaks from room temperature $28^{\circ} \mathrm{C}$ to $550^{\circ} \mathrm{C}$. The first two endothermic peaks with onset temperatures as 93. $1^{\circ} \mathrm{C}$ and $129.2^{\circ} \mathrm{C}$ are observed respectively due to the two phase transformation of PSAN. The Third endothermic peak with onset temperature $163.8^{\circ} \mathrm{C}$ represents the absorption of heat for the melting of PSAN. And the fifth endothermic peak with onset temperature $275^{\circ} \mathrm{C}$ shows the absorption of heat for the final and complete decomposition of the PSAN.
Figure 5 shows A comparison of DSC curves for AN, PSAN, preheated PSAN, PSAN prepared by solid mixing and fresh PSAN. These DSC curves show that all the oxidizer endothermic peaks from room temperature $28^{\circ} \mathrm{C}$ to $600^{\circ} \mathrm{C}$. The first two endothermic peaks represent phase transformation but the differences are in peaks temperature or the onset temperature shifts depend on the type of PSAN. Third peak represents heat absorption for melting of treated and non-treated AN. The last peak shows absorption of heat for final and complete decomposition of treated and nontreated AN. It is noticed that melting temperature of treated AN has shifted. Fresh PSAN and stored PSAN shows nearly same result but little shifting occur in their melting and decomposition onset temperature. In the present research solid mixed PSAN shows faster decomposition as compared to pure AN and solution mixed PSAN.

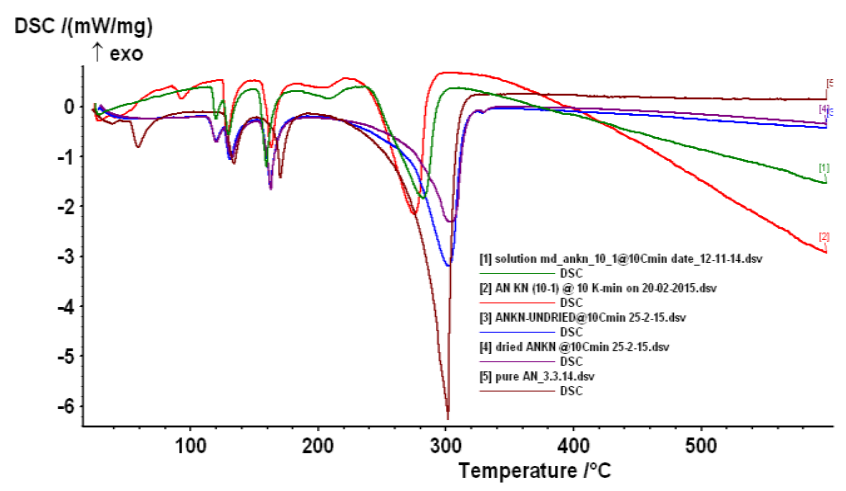

Fig-5: DSC of Oxidisers

\subsubsection{Differential Scanning Calorimetry of}

\section{Propellant Samples}

Table 3 presents the temperatures at which endothermic and exothermic process of virgin PSAN-HTPB and the propellant samples with catalysts takes place. The endothermic peaks are almost at same temperature for six propellant samples, Only PSAN-HTPB propellant sample with $\mathrm{Cu}$-Co-III has somehow lesser endothermic peaks. But there is a clear difference in the exothermic peak temperatures between the virgin PSAN-HTPB sample and the PSAN-HTPB samples with catalyst. There are three or more than three exothermic peaks for all the propellant samples except, Propellant sample with $2 \% \mathrm{Cu}$-Co-III catalyst which has two exothermic peaks.

From the individual DSCthermograms for virgin PSANHTPB and PSAN-HTPB propellant with $2 \% \mathrm{Cu}-\mathrm{Co}-\mathrm{I}, \mathrm{Cu}-$ $\mathrm{Co}-\mathrm{II}$ and $\mathrm{Cu}-\mathrm{Co}-\mathrm{III}$ mixed metal oxides respectively, we can notice that the endothermic peak temperature is almost similar for all the propellant samples. However, there is a marked difference in the exothermic peaks which suggest that the decomposition of the propellant samples with copper cobalt mixed metal oxides is rapid at a certain temperature. 
Table -3:DSC results of different propellants samples

\begin{tabular}{|c|c|c|c|c|c|c|c|}
\hline Samples & $\begin{array}{c}\text { Samples } \\
\text { mass }\end{array}$ & \multicolumn{3}{|c|}{$\begin{array}{l}\text { Endothermic } \\
\text { peaks }\left({ }^{\circ} \mathrm{C}\right)\end{array}$} & \multicolumn{3}{|c|}{$\begin{array}{l}\text { Exothermic } \\
\text { peaks }\left({ }^{\circ} \mathrm{C}\right)\end{array}$} \\
\hline $\begin{array}{l}\text { Virgin } \\
\text { PSAN- } \\
\text { HTPB }\end{array}$ & 3.84 & 133.3 & 164.3 & - & 220 & 239.1 & 461.0 \\
\hline $\begin{array}{l}\text { Virgin } \\
\text { PSAN- } \\
\text { HTPB }\end{array}$ & 3.52 & 133.6 & 164.2 & - & 213.5 & 243.3 & 413.1 \\
\hline $\begin{array}{l}\text { Virgin } \\
\text { PSAN- } \\
\text { HTPB } \\
\text { (SM) } \\
\end{array}$ & 3.90 & 133.9 & 173.5 & 270.0 & 226.3 & 391.6 & 446.2 \\
\hline $\begin{array}{l}\text { Virgin } \\
\text { PSAN- } \\
\text { HTPB } \\
(80 / 20)\end{array}$ & 3.48 & 134.0 & 166.3 & - & 221.4 & 383.6 & 413.3 \\
\hline $\begin{array}{l}\text { PSAN- } \\
\text { HTPB } \\
\text { Cu-Co-I }\end{array}+$ & 3.70 & 121.6 & 160.4 & - & $\begin{array}{l}237.0, \\
266.0\end{array}$ & 380.9 & 486.4 \\
\hline $\begin{array}{l}\text { PSAN- } \\
\mathrm{HTPB} \\
\mathrm{Cu}-\mathrm{Co}-\mathrm{II}\end{array}+$ & 3.92 & 131.3 & 162.2 & - & 236.5 & $\begin{array}{l}392.6, \\
436.6\end{array}$ & $\begin{array}{l}481.9, \\
506.3\end{array}$ \\
\hline $\begin{array}{l}\text { PSAN- } \\
\text { HTPB+ } \\
\text { Cu-Co-III }\end{array}$ & 3.84 & 133.5 & 166.5 & - & 229.1 & 375.2 & - \\
\hline
\end{tabular}

DSC curve of virgin PSAN-HTPB Propellant sample which illustrates the endothermic and exothermic behaviors of it. The heating rate was $10 \mathrm{k} / \mathrm{min}$. Two endothermic peaks of onset temperature as $133.33^{\circ} \mathrm{C}$ and $164.2^{\circ} \mathrm{C}$ are observed. The first endothermic represents phase changes of virgin PSAN-HTPB propellant sample and the second endothermic peak represents absorption of heat for the melting of propellant sample. On further heating the three exothermic peaks are absorbed with onset temperatures as $220.0^{\circ} \mathrm{C}$, $239.1^{\circ} \mathrm{C}$ and $416.0^{\circ} \mathrm{C}$ respectively. The net enthalpy evolved is $1282 \mathrm{~J} / \mathrm{g}$ for the first two exothermic peaks and $2542 \mathrm{~J} / \mathrm{g}$ for third exothermic peak.

The DSC thermogram of virgin PSAN-HTPB preheated propellant illustrates the endothermic and exothermic behaviors of it, which was heated at $60^{\circ} \mathrm{C}$ for 3 hours before subjecting to DSC analysis. Nearly the same processes evolve. The same two endothermic peaks with onset temperature $133.6^{\circ} \mathrm{C}$ and $164.2^{\circ} \mathrm{C}$ are observed. Three exothermic peaks with onset temperatures are $213.5^{\circ} \mathrm{C}$, $243.3^{\circ} \mathrm{C}$ and $413.1^{\circ} \mathrm{C}$ are also observedhowever the net enthalpy change is $1103 \mathrm{~J} / \mathrm{g}$ for first two exothermic peaks and $1926 \mathrm{~J} / \mathrm{g}$ for third exothermic peak found lower as compared to the unheated propellant.

The DSC thermogram of virgin PSAN-HTPB propellant sample illustrates the endothermic and exothermic behaviors of it in which the PSAN was prepared by solid mixing of $\mathrm{AN}$ and $\mathrm{KN}$. The two endothermic peaks with onset temperatures $133.9^{\circ} \mathrm{C}$ and $173.5^{\circ} \mathrm{C}$ are observed where first one is nearly same but the $2^{\text {nd }}$ one is higher. The exothermic peak temperatures are $226.3^{\circ} \mathrm{C}, 391.6^{\circ} \mathrm{C}$ and $446.2^{\circ} \mathrm{Care}$ observed which differ from solution mixing PSAN-HTPB propellant sample. The heat evolved during first exothermic peak is $1244 \mathrm{~J} / \mathrm{g}$ which is higher as compared to solution mixing PSAN-HTPB virgin sample. The $2^{\text {nd }}$ exothermic peak shifts to higher temperature side and is very close to $3^{\text {rd }}$ exothermic peak with total $1267 \mathrm{~J} / \mathrm{g}$ heat evolved.

The DSC thermogram of PSAN-HTPB 80/20 sample illustrates the endothermic and exothermic behavior of it. The endothermic peaks with onset temperatures $134^{\circ} \mathrm{C}$ and $166.3^{\circ} \mathrm{C}$ are nearly same as compare to the solution mixing virgin propellant samples. It is noticed that the three exothermic peaks with onset temperatures $221.4^{\circ} \mathrm{C}, 383.6^{\circ} \mathrm{C}$ and $413^{\circ} \mathrm{C}$ differ from the exothermic peaks of solution mixed PSAN-HTPB virgin samples but they are similar to the solid mixed PSAN-HTPB virgin sample. The 1134J/g net enthalpy evolved during first exothermic peak and $1086 \mathrm{~J} / \mathrm{g}$ during $2^{\text {nd }}$ and $3^{\text {rd }}$ exothermic peak is lesser than solid mixed PSAN-HTPB virgin sample.

The DSC thermogram of PSAN-HTPB propellant with $2 \%$ $\mathrm{Cu}-\mathrm{Co}-\mathrm{I}$ illustrates the endothermic and exothermic behavior of it. The heating rate is same like in other propellant samples. Two endothermic peaks with onset temperatures $121.6^{\circ} \mathrm{C}$ and $160.4^{\circ} \mathrm{C}$ are observed which are same like all other virgin propellant samples but the onset temperatures are at lower temperature side. The drastic changes have been observed in the exothermic peaks and the onset temperature exothermic reactions and the heat evolved. Four exothermic peaks are observed with onset temperatures $237^{\circ} \mathrm{C}, \quad 266^{\circ} \mathrm{C}, \quad 380.9^{\circ} \mathrm{C}$ and $486.4^{\circ} \mathrm{C}$ respectively whereas the virgin sample has only 3 peak with onset temperatures $220^{\circ} \mathrm{C}, 239.1^{\circ} \mathrm{C}$ and $416^{\circ} \mathrm{C}$. This indicates that the $\mathrm{Cu}$-Co-I alters the reaction mechanism of the propellant. It also reflects that the rate of reaction being altered on the addition of $\mathrm{Cu}$-Co-I.

The DSC heating thermogram of PSAN-HTPB propellant with $2 \% \mathrm{Cu}$-Co-II illustrates the endothermic and exothermic behavior of it. Two endothermic peaks and five exothermic peaks are observed on heating it from $28^{\circ} \mathrm{C}$ $800^{\circ} \mathrm{C}$. The endothermic peaks are nearly similar to endothermic peaks of virgin propellant samples. The drastic changes are observed in the exothermic peaks with onset temperatures and the net enthalpy evolved. The onset temperatures and number of peaks are higher which indicates that $\mathrm{Cu}-\mathrm{Co}-\mathrm{II}$ enhances the decomposition of propellant but at different temperature region. These results reflect that the decomposition processes are spread over on a wider temperature segment and heat evolved also in steps which make the propellant hard to combust. So it can be said that enhancement at same temperature can produce higher rate of decomposition as well as maximum net enthalpy.

The DSC thermogram PSAN-HTPB propellant sample with $2 \% \mathrm{Cu}-\mathrm{Co}-\mathrm{III}$ illustrates the endothermic and exothermic behavior of it. Two endothermic peaks and two exothermic peaks are observed on heating the propellant from room temperature $28^{\circ} \mathrm{C}$ to $600^{\circ} \mathrm{C}$. It is noticed that the endothermic peaks are similar to the endothermic peaks of all virgin propellant samples. Unlike the $\mathrm{Cu}$-Co-I, II's effect of rate of decomposition of PSAN-HTPB solid propellant sample $\mathrm{Cu}$-Co-III has single peak point with onset 
temperature $229.1^{\circ} \mathrm{C}$. This is similar to the endothermic as well as the exothermic peaks of solid mixed PSAN-HTPB virgin propellant. The enthalpy change during the process is about $1424 \mathrm{~J} / \mathrm{g}$. The steep rise in temperature indicates the fast reaction and higher enthalpy change comparatively per unit time.

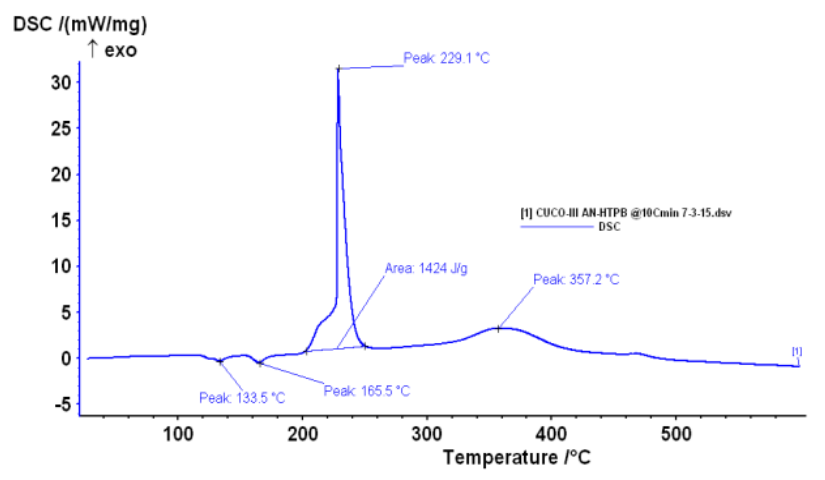

Fig-6: DSC result of propellant sample with $2 \% \mathrm{Cu}-\mathrm{Co}-\mathrm{III}$

Figure 7 shows the comparison of DSC thermogram which illustrates the endothermic and exothermic behavior of PSAN-HTPB propellant samples. It is noticed that the endothermic peaks of all the propellant samples are nearly same. The drastic changes in exothermic peaks have been observed. The exothermic peak of Propellant with $\mathrm{Cu}-\mathrm{Co}-\mathrm{III}$ has highest hike and its $2^{\text {nd }}$ exothermic peak has broaden. The resulting higher heat generation at single temperature point makes the propellant to generate sufficient heat for the combustion process. So it can be said that the $\mathrm{Cu}-\mathrm{Co}$-III has capability to enhance the burn rate. Solid mixed PSANHTPB virgin sample and PSAN-HTPB 80/20 sample have comparatively same endothermic and exothermic peaks. The exothermic peaks of remaining all other samples are distributed at different temperature points that results the distribution of heat at different temperature causes lack of sufficient heat generation for the combustion to sustain.

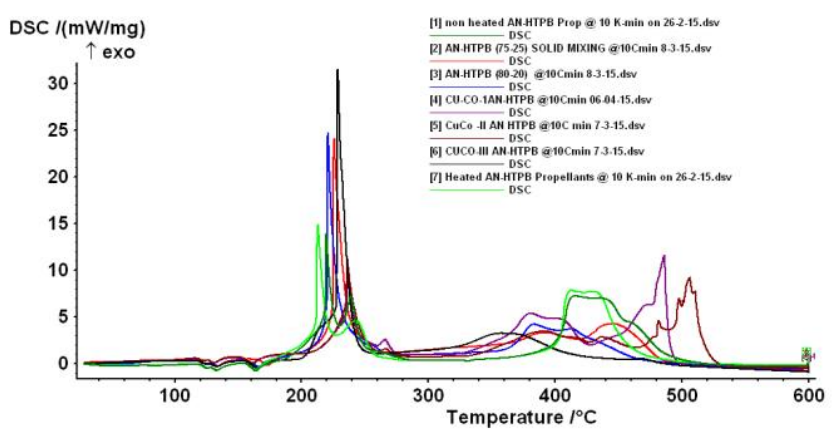

Fig-7: DSC of propellant sample

\subsection{Burn Rate Studies}

The burn rate studies at various pressures were carried out using a Crawford High Pressure Strand Burner. The propellant strands were electrically ignited and the time taken to burn for $50 \mathrm{~mm}$ length of the strand was recorded and then burn rate was calculated by dividing length by time taken to burn the length. Nitrogen gas was used to pressurize the strand burner to simulate the operating chamber pressure conditions.

It is observed that the propellant made from PSAN solid mixing method and solution mixing method with $2 \% \mathrm{Cu}-$ Co-III burns smoothly in this pressure range. Other propellant samples either did not burn or burnt only $2-3 \mathrm{~cm}$ and extinguished after that. The burning rate -pressure data for the propellant burnt completely are presented in figure 8 . It is observed that the increasing the pressure increases the burn rate of propellants investigated in the present work. However the catalyzed propellant is more sensitive to pressure effect as compared to virgin propellant. Catalyzed propellant has lower burn rate compared to virgin propellant till 400 psi but above this pressure it crosses the burn rate of virgin propellant. This increase of burn rate at pressure above 400psi for catalyzed propellant shows that $\mathrm{Cu}-\mathrm{Co}-\mathrm{III}$ catalyst is more active for PSAN-HTPB propellant.

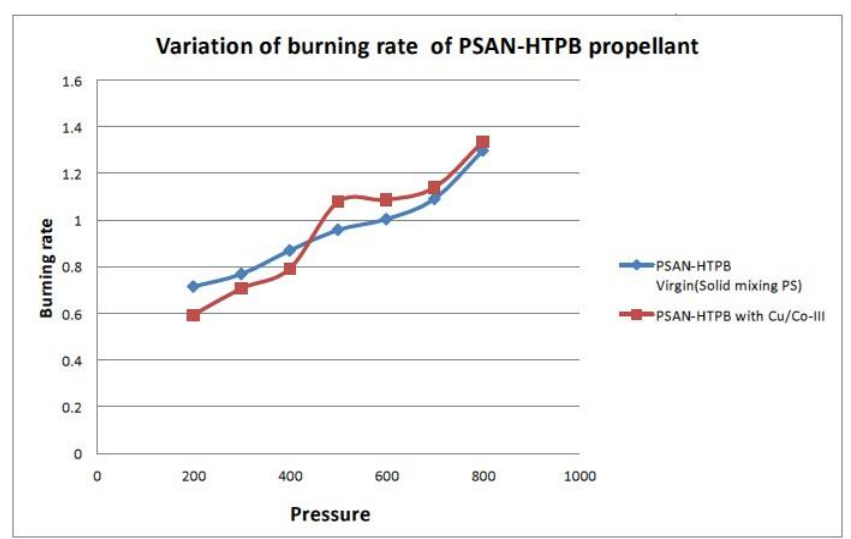

Fig 8: Variation of burning rate with pressure of PSANHTPB propellant with and without catalyst.

\section{CONCLUSIONS}

The following conclusions can be drawn from the present investigations on the combustion characteristics of PSANHTPB composite solid propellants with and without the copper cobalt mixed metal oxides.

1. The TGA thermograms of solid mixed virgin propellant, 80/20 virgin propellant, and propellant sample with $2 \% \mathrm{Cu}$-Co-III catalysts are almost similar whereas a rapid decomposition can be observed. All the thermograms show a three staged decomposition in which the rate of decomposition is highest in the 2 nd stage.

2. Form the Simultaneous Thermal Analyzer it was noticed that the endothermic peaks are almost at same temperature for all the propellant samples but there is a clear difference in the exothermic peak temperatures between the virgin PSAN-HTPB sample and the propellant sample with $2 \% \mathrm{Cu}-\mathrm{Co}-\mathrm{III}$. Propellant of 80/20 PSAN-HTPB and solid mixed virgin propellant have similar endothermic and exothermic peaks like propellant sample with $2 \% \mathrm{Cu}-\mathrm{Co}-\mathrm{III}$. 
3. There are four exothermic peaks for the propellant sample with $2 \%$ Cu-Co-I catalyst, five exothermic peaks for the propellant sample with $2 \% \mathrm{Cu}-\mathrm{Co}-\mathrm{II}$ and two exothermic peaks for the propellant with $2 \% \mathrm{Cu}-$ Co-III. It indicates the different effects of various molar ratios of copper cobalt mixed metal oxides also indicate that the rate of heat release is maximum for propellant with $2 \% \mathrm{Cu}-\mathrm{Co}-\mathrm{III}$

4. Results show that $\mathrm{Cu}-\mathrm{Co}-\mathrm{I}$ and $\mathrm{Cu}-\mathrm{Co}-\mathrm{II}$ either effect the combustion reaction mechanism of PSAN-HTPB propellant or they have a negative effect on the reaction mechanism, Whereas the catalyst $\mathrm{Cu}-\mathrm{Co}$-III accelerate the rate of heat release and weight loss confirming it as a good catalyst for PSAN-HTPB propellant.

5. From the phase stabilization point of view, the addition of $10 \%$ potassium nitrate to ammonium nitrate is quite effective to shift the endothermic peaks in the higher temperature side.

6. It has been observed that the addition of $2 \% \mathrm{Cu}-\mathrm{Co}-\mathrm{III}$ increases the burning rate of the propellant composition studied in the present investigation. It is observed that the increasing the pressure increases the burn rate of propellant with $2 \% \mathrm{Cu}-\mathrm{Co}-\mathrm{III}$ and PSAN-HTPB virgin propellant (where PSAN was prepared by solid mixing) burnt smoothly while the other propellants didn't sustain burning. The propellant with $2 \% \mathrm{Cu}-\mathrm{Co}-\mathrm{III}$ is more sensitive to pressure effect as compared to solid mixed virgin propellant but this effect comes above 400psi. This increase in burn rate with pressure for $\mathrm{Cu}$ Co-III catalyzed propellant shows that the Copper cobalt mixed metal oxide catalyst with 2 molar ratios is more active for the propellants considered in the present work whereas catalyst $\mathrm{Cu}-\mathrm{Co}-\mathrm{I}$ and $\mathrm{Cu}-\mathrm{Co}-\mathrm{II}$ do not effect in the combustion of PSAN-HTPB composite propellant.

7. Although efforts of mixed metal oxide on the combustion of PSAN-HTPB based composite solid propellant and phase stabilization effect of AN have been made to explain the results obtained in the present work. However it is felt that more elaborate investigation on different aspects of combustion with catalysts is required to reach any specific conclusion.

\section{FUTURE SCOPE OF WORK}

In the present work an attempt has been made to synthesize copper-cobalt mixed metal oxides by citric acid complexing method. The synthesized catalysts were added to the PASNHTPB composite formulations which were then subjected to burn rate measurement and thermal degradation studies. The ammonium nitrate was made phase stabilized by incorporating $10 \%$ potassium nitrate. Apart from these, there are several other aspects which can be investigated and studied. Some of the important areas which can be explored are
1. The copper cobalt mixed metal oxides can be synthesized with different $\mathrm{Cu}-\mathrm{Co}$ molar ratios in initial reactants. The catalysts can be prepared at different calcination temperatures ranging from $400{ }^{\circ} \mathrm{C}$ to 900 ${ }^{\circ} \mathrm{C}$. In the present work the $\mathrm{CA}-\mathrm{Cu}-\mathrm{Co}$ precursors were calcined only at $600{ }^{\circ} \mathrm{C}$.

2. The copper cobalt mixed metal oxides can be synthesized by other synthesizing techniques which may improve the effect of mixed metal oxides on PSAN based composite solid propellant.

3. It is worthwhile to study the PSAN-HTPB based composite propellant where the PSAN can be prepared by adding $0.3-20 \%$ of other chemicals which might stabilize as well as increase the decomposition rate of PSAN-HTPB based composite propellant. Such study will be a good achievement to make propellant with chlorine free exhaust.

4. The use of different fine/course ratio of oxidizer along with different proportions of catalysts will be very helpful to tailor the burning rate of PSAN based composite solid propellants.

5. To increase the burning rate of PSAN based propellant the blending of fuel binder can be done in definite proportion. Such study might be useful to make ecofriendly propellant with high performance.

6. A study of PSAN based propellants by using fast burning fuel binders such as PTHF and PDMS with varying percentage of copper-cobalt mixed metal oxide catalysts will be much beneficial to have a propellant with wide range of applications.

\section{ACKNOWLEDGEMENT}

The authors would like to acknowledge the technical help and guidance of Prof. Dr. J. K. Prasad, Prof. Priyank Kumar, Mr. Satish Kumar, Mr. Sachinder, Mr. Ashok Kumar, Mr. Gangaram, Mr. Arun Mishra, Mr. Jitram, and Mr. Hareram, who have supported and helped us in our work.

\section{REFERENCES}

\section{Basic format for books:}

[1] Summerfield M.; Sutherland G. S.; Webb M. J.; Tabock H. H.; and Hall K. P.

[2] J. K. Author, "Title of chapter in the book," in Title of His Published Book, xth ed. City of Publisher, Country if not

\section{Basic format for periodicals:}

[3] Makoto kohga and Kayoko Okamoto "Thermal decomposition behavior and burning characteristics of AN/PTHF/Glycerin composite propellant" NDA JapanArticle 10 Oct 2010.

[4] Makoto kohga, Tomoki Naya and Kayoko Okamoto "Burning characteristics of AN based propellant with 
HTPB/PTHF blend binder" NDA Japan Article 24 Jan 2012.

[5] TamokiNaya and MakotiKohga "Burning characteristics of AN based propellant supplemented with $\mathrm{Fe}_{2} \mathrm{O}_{3}$ " Full paper DOI: 10.1002/ Prep.201200159.

\section{Basic format for reports:}

[6] Summerfield M., "Solid Propellant Combustion Mechanism Research", Annual Report, 1 Nov 1972 30 Sep 1973, Report date August 1973.

[7] L.T. Deluca, L. Galfetti, F. Maggi, G. Colombo et al “ Burning of metalized composite solid propellant towards nano-metric fuel size" Journal SP lab Campus Bovisa I-20156 Milan Itly.

[8] Votsmeier M.; Kreuzer T. and Lepperhoff G., "Automobile Exhaust Control. Automobile Exhaust Control", Wiley-VCH Verlag GmbH \& Co. KGaA, Weinheim, 2005.

[9] E. W. Price, S. R. Chakravarthy, R. K. Sigman, R. Jeenu, J. M. Freeman, and J. M. Seitzman, "Combustion Mechanisms of Heterogeneous Solid Propellants", Final Report, 1 March 1995 - 1 June 1999, Report date Feb 2000.

[10] G. S. Pearson and P. W. M. Jacobs "Mechanism of the Decomposition of Ammonium Perchlorate", Technical Report May 1969.

\section{Basic format for journals (when available \\ online):}

[11] Beckstead M. W.; Derr R. L.; and Price C. F., "A model of Composite Solid Propellant Combustion Based on Multiple Flames", AIAA Journal, Vol. 8, 1970, pp. $2200-2207$.

[12] "The Burning Mechanism of Ammonium Perchlorate", Academic Press, New York, Vol. 1, 1960, pp. 141 182.

[13] M. Pandey and S. Jha" Pressure effect study on burning rate of AN-HTPB propellant", Academic Journal Jan 2012 vol. 107

[14] Handley J. C. and W. C. Strahle, "Behaviour of Several Catalysts in the Combustion of Solid Propellant Sandwiches", AIAA Journal, Vol. 13, 1975, pp. 5 - 6.

[15] Fong C. W. and B. L. Hamshere, "The Mechanism of Burning Rate Catalysis in Composite HTPB-AP Propellant Combustion", Combustion and Flame Journal, Vol. 65, 1986, pp. 61 - 69.

[16]Fong C. W. and B. L. Hamshere, "The Mechanism of Burning Rate Catalysis in Composite Propellants by Transition-Metal Complexes", Combustion and Flame Journal, Vol. 65, 1986, pp. 71 - 78.

[17]Fong C. W. and R. F. Smith, "The Relationship Between Plateau Burning Behaviour and Ammonium Perchlorate Particle Size in HTPB-AP Composite Propellants", Combustion and Flame Journal, Vol. 67, 1987, pp. 235 - 247.

[18] Yin J.; B. Li, K. Wang and B. Chen, "Combustion Mechanism of a Negative Pressure Exponent
Composite Solid Propellant", Journal of Propulsion and Power, Vol. 8, pp. 37 - 44.

[19] Suresh Methew, K. Krishan and K.N. Ninan "Effect of energetic material on thermal decomposition of PSANan eco- friendly oxidizer" VSSC Thrivandram. Defense science journal Vol.49, NO-1 Jan 1999.

[20] Adkins H.; Connor R., "The Catalytic Hydrogenation of Organic Compounds over Copper Chromite", American Chemical Society Journal, Vol. 53, 1931, pp. 1091 1095.

[21] Menon P. G.; and Delmon B., "Handbook of Heterogeneous Catalysis", G. Ertl, H. Knozinger and J. Weitkamp, Eds., Vol. I, Wiley-VCH, Weinheim. 1997, pp. $100-118$.

[22] Kawamoto A.M.; Pardini L.C.; Rezende L.C., "Synthesis of Copper Chromite Catalyst", Aerospace Science and Technology Journal, 2004, Vol. 8, pp. 591 - 598.

[23] Valde's-Soli's T.; Marba'n G.; Fuertes A.B., "Nanosized Catalysts for the Production of Hydrogen by Methanol Steam Reforming", Catalysis Today Journal, 2006, Vol. 116, pp. 354 -360.

[24] Patron L.; Pocol V.; Carp O., "New Synthetic Route in obtaining Copper Chromite (I): Hydrolysis of some Soluble Salts", Materials Research Bulletin Journal, 2001, Vol., pp. 1269 - 1276.

[25] Kumar A.; Yusuf S.M.; and Yakhmi J.V., "Synthesis and Magnetic Properties of PVP coated CopperChromium Hexacyanide Nanoparticles" Journal of Physics: Conference Series, 2010, Vol. 200.

[26] Patil K.C.; Aruna S.T.; Mimani T., "Combustion Synthesis: An Update", Current Opinion in Solid State and Materials Science Journal, 2002, Vol. 6, pp. 507 512.

[27] Shiau C.Y.; and Tsai J. C., "Cu/SiO2 Catalyst Prepared by Electroless Method", Journal of Chemical Technology and Biotechnology, 1998, Vol. 73, pp. 414 $-420$.

[28] Huang W.; Li H.; Zhu B.; Feng Y.; Wang S.; Zhang S., "Selective Hydrogenation of Furfural to Furfuryl alcohol over Catalysts Prepared via Sonochemistry", 2007, UltrasonicsSonochemistry Journal,Vol.14, pp. 67 $-74$.

[29] LI Wei; CHENG Hua, "Synthesis and Characterization of Cu-Cr-O Nanocomposites", 2007, Journal of Central South University of Technology, Vol. 9, pp. $750-755$.

[30] Ma Z.; Xiao Z.; A. J.; Bokhoven V.; Liang C., “A NonAlkoxide Sol-Gel route to highly Active and selective $\mathrm{Cu}-\mathrm{Cr}$ Catalysts for Glycerol Conversion" Journal of Materials Chemistry, 2010, Vol. 20, pp. 755-760.

[31] Y. B. R. D. Rajesh; R. S. Dubey, "Sol-Gel Synthesis and Characterization of Nanocrystalline Spinel LiMn2O4 for Battery Applications", Nanoscience and Nanoengineering Journal, 2013, Vol. 1, pp. 139 - 141.

[32] M.H. Habibi; F. Fakhri, "Sol-gel Combustion Synthesis and Characterization of Nanostructure Copper Chromite Spinel", Journal of Thermal Analysis and Calorimetry", 2014, Vol. 115, pp. 1329 - 1333.

[33]R. Prasad; P. Singh, "Applications and Preparation Methods of Copper Chromite Catalysts: A 
Review”, Bulletin of Chemical Reaction Engineering \& Catalysis Journal, 2011, Vol. 6, pp. 63 - 113.

\section{Basic format for paperspresented at conferences}

\section{(when available online):}

[34] Price E. W.; R. K. Sigman, S. R. Chakravarthy and P. D. Paulsen, "Hot Stage Microscope Studies of Decomposition of Propellant Ingredients", Proceedings of the $30^{\text {th }}$ JANNAF Combustion Meeting, II, November 1993, JANNAF, pp. 289 - 296.

[35] Makoto Kohga and Seako Nishino "Burning characteristics of AN based propellant supplemented with ammonium dichromate" Department of applied chemistry, NDA JAPAN. Sep 16 2008. DOI: 10.1002/Prep.200800060. Management, 2010, Vol. 2, pp. $323-330$.

[36] Kym M. Ide "Composite propellant with bi-plateau burning behavior" defense science and technology document, commonwealth of Australia November 2002.

[37] TamokiNaya and MakotiKohga "Burning Characteristics of AN based propellant supplemented with $\mathrm{MnO}_{2}$ " Full Paper DOI: 10.1002/ Prep.201200160.

\section{BIOGRAPHIES}

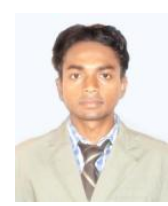

Mr. Rajan Lakra M.E in Space Engineering \& Rocketry from BIT, Mesra. Ranchi, India ,After completing B.E in Aeronautical Engineering From Anna University, presently working as Assistant Prof at Institute of Aeronautical Engineering, Hyderabad

Email id: rajanlakra@gmail.com

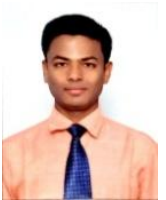

Mr. Cholleti Eshwar Reddy pursuing M.Tech in Thermal Branch from PRIT affiliated to JNTU - Hyderabad, India. After completing B.Tech in Aeronautical Engineering from esteemed MLR Institute of Technology affiliated to JNTU - Hyderabad with distinction.

Email id: Eshwar.ch1808@gmail.com

Prof. Dr Puran Chandra Joshi Ph.D in Rocket Combustion process from BIT Mesra. FormerVC, Dean and HOD at BIT Mesra.

Dr. Narendra Yadav, Ph.d in Solid Rocket propellant, Working as Research Scientist III at BIT, Mesra 